CIUDAD Y TERRITORIO

ESTUDIOS TERRITORIALES

ISSN(P): 2697-231X; ISSN(E): 2697-2328

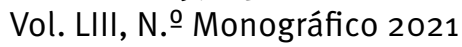

Págs. 139-158

https://doi.org/10.37230/CyTET.2021.M21.08

CC BY-NC-ND

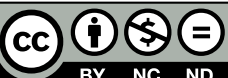

\title{
Territorio, lugar e identidad en los barrios vulnerables. El Barrionalismo como práctica política
}

\author{
Sara PORRAS-SÁNCHEZ ${ }^{(1)}$ \\ Francesca DonATI (2)
}

(1)Profesora de la Universidad Complutense de Madrid

${ }^{(2)}$ Investigadora de la Universidad Pablo de Olavide

RESUMEN: En el artículo se aborda el estudio de los conflictos urbanos desde la perspectiva del barrio como espacio depositario de sentidos compartidos. Analizando cualitativamente los espacios desde su triple dimensión, material, simbólica e imaginaria. En concreto desarrollando la importancia del sentimiento de identidad como elemento preconstitutivo para el despliegue del barrionalismo como práctica política emergente en los barrios con características socioeconómicas de vulnerabilidad. El espacio del barrio cobra relevancia, como producto de las tensiones globalizadoras, como espacio de re-construcción comunitaria, al mismo tiempo que es fruto del cambio en la geopolítica internacional haciendo parte fundamental de las ciudades globales como nuevo agente global. En esta aproximación analizamos cualitativamente 3 barrios de la Región de Madrid.

PALABRAS CLAVE: Vulnerabilidad; Madrid; Barrionalismo; Lugar; Identidad.

\section{Territory, place and identity in vulnerable neighborhoods. Barrionalismo as a political practice}

ABSTRACT: The article addresses the study of urban conflicts from the perspective of the neighborhood as a depository space for shared meanings. It provides a qualitative analyses of the spaces looking at their triple dimension: material, symbolic and imaginary. Specifically, the discussion develops the importance of identity as a preconstitutive element for the deployment of "barrionalismo" as an emerging political practice in neighborhoods with vulnerable socio-economic characteristics. The

Recibido: 06.07.2020; Revisado: 09.12.2020

Correo electrónico: sporrass@ucm.es; N. ORCID: https://orcid.org/0000-0002-8003-1506

Correo electrónico: francesca.donati11@studio.unibo.it; N. ${ }^{\circ}$ ORCID: https://orcid.org/0000-0003-2183-7726

Las autoras agradecen los comentarios y sugerencias realizados por los evaluadores anónimos, que han contribuido a mejorar y enriquecer el manuscrito original. 
neighborhood space becomes relevant as a product of globalizing tensions, a space for community re-construction, and at the same time it is the result of international geopolitics change, making it a fundamental new global agent for cities. With this approach we qualitatively analyze 3 neighborhoods in Madrid Region.

KEYWORDS: Vulnerability; Madrid; Barrionalismo; Place; Identity.

\section{Introducción ${ }^{1}$}

I estudio de la ciudad y los procesos urbanos están atravesados por un juego constante de dimensiones, escalas y conflictos que constituyen este campo de análisis en un espacio privilegiado para la práctica sociológica. En las grandes urbes el capitalismo agresivo se hace con el territorio produciendo lo que Saskia Sassen Ilama expulsiones (SASSEN, 2015) y si bien en Madrid las dinámicas de segregación se remontan a los años '50 con el plan Bidagor ${ }^{2}$ que:

"dividía la ciudad en tres partes acordes a sus recursos naturales y a las características de la población que habitaba en ella y establecía unas normativas diferentes para cada una de esas tres partes" (LEAL MALDONADO, 2002: 60),

estas dinámicas de desigualdad social y territorial han ido polarizándose a lo largo de los años.

En este artículo vamos a centrar nuestra atención en la dimensión espacial articulada a través del concepto de barrio. Por un lado, como espacialidad conectada a la ciudad en tanto que parte de un conjunto, pero, sobre todo, desde su evocación más popular. "El barrio surge como rasgo distinto e indicador de esa situación de explotación y desigualdad dentro de la unidad espacial ciudad". (GRAVANO, 2005: 12). Donde los límites administrativos se difuminan en favor de otras consideraciones articuladas a partir de su análisis como espacio construido materialmente con una trama y unos trazados concretos, su condensación temporal de luchas y prácticas comunitarias, así como la construcción de significados compartidos por parte de sus habitantes. Todo ello entendido de una forma dinámica y por ello sujeta a una constante reconfiguración, pero donde parece posible re-componer ciertos "mapas mentales" (GouLd \& WHITE, 1986) con los que los barrios se van reconociendo.

\footnotetext{
1 Los datos que se manejan son el resultado de un proyecto más amplio Vulnerabilidad, Participación y Ciudadanía (S2015/HUM-3413 VUPACI-CM) financiado por la Comunidad de Madrid y el Fondo Social Europeo. En concreto se analizan 31 entrevistas realizadas a distintos perfiles en los barrios de Abrantes y Entrevías, de la ciudad de Madrid y Reyes Católicos de Alcalá de Henares. Estos barrios son espacios urbanos con altos niveles de vulnerabilidad y, a pesar de
}

Queremos poner el foco en las posibilidades de apropiación de los espacios por parte de las personas que los habitan. Situando la escala de barrio como el marco explicativo a partir del cual se trazan posibles itinerarios. Como el cruce entre la espacialidad, la historia y la significación de los lugares operan en la construcción identitaria en los barrios. Y como la intersección de estas dimensiones facilita o limita el desarrollo de prácticas barriales vinculadas al territorio y al habitar de los residentes. El análisis Parte de una investigación que hemos venido desarrollando durante cuatro años en la comunidad de Madrid en la que hemos analizado el desarrollo de siete espacialidades definidas por su relación con la vulnerabilidad. Para ello, con base al índice de vulnerabilidad (IVU) elaborado por Pedro UcEDA (2017) se seleccionaron estas localizaciones atendiendo a las trayectorias de vulnerabilidad que se daban en estos lugares.

En este texto analizamos el barrio de Entrevías, en el distrito de Vallecas, el barrio de Abrantes, en el distrito de Carabanchel y el barrio de los Reyes Católicos en el Distrito II del municipio de Alcalá de Henares. La selección de estos espacios tiene que ver con la voluntad de indagar cuáles son los elementos que contribuyen a que las personas nos apropiemos de los espacios que habitamos. Por ello hemos seleccionado tres barrios cuyas características materiales son muy similares pero que difieren fundamentalmente en la identidad y el discurso que vecinas y vecinos hacen de dichos lugares. Articulamos el análisis sobre la base de 31 entrevistas realizadas durante el periodo de 2017 a 2019 a diferentes informantes clave. Las representaciones espaciales que encontramos, unido al trabajo de campo y observación que hemos realizado sobre el territorio nos ha permitido identificar una serie de elementos que, sistematizados, aterrizan estas cuestiones

haber tenido un desarrollo urbanístico similar y coincidente en el tiempo, las estrategias políticas y los sentimientos de identidad y arraigo sobre el lugar son muy diferentes, lo que nos lleva a defender la pertinencia de esta perspectiva analítica para su estudio.

2 Hace referencia al Plan General de Ordenación Urbanística de Madrid de 1946. Llamado así por el nombre del urbanista que inició su diseño, Pedro Bidagor Lasarte. 
sobre los lugares y contribuyen a profundizar en el debate que estamos planteando. Es esto lo que entendemos como la práctica política del barrionalismo: un accionar cotidiano, vinculado con la noción de lugar - como espacialidad con sentido y a caballo de varias escalas- re-creado discursiva y materialmente que politiza los conflictos generando una identidad que transforma el campo político. No todos los lugares conjugan las características que posibilitan la práctica política del barrionalismo y consideramos que justamente este artículo pretende sistematizar los elementos que hemos identificado para aproximarnos a dicha noción, mediante el método comparativo de tres espacios de la ciudad cuyas características sociodemográficas son similares pero cuyas identidades espaciales son diferentes.

Una característica del análisis tiene que ver con el tratamiento cruzado de los conceptos, atendiendo a estas realidades en un juego de doble dimensión: una de carácter más material y otra la representada, la apropiada.

Se trata por lo tanto de entender cómo los barrios operan dentro del lenguaje de las ciudades. (SUDJIC, D., 2017). La ciudad como una escritura inacabada dispuesta para ser interpretada. Un juego inestable, donde los habitantes forman parte de ese mismo lenguaje produciéndolo y siendo reproducidos. La ciudad como estructura portadora de conflictos en torno al ejercicio y las resistencias del poder, la ciudad como cartografía, ubicada en una trama y paisajes urbanos que la atraviesan y condicionan; La ciudad como el espacio de las prácticas cotidianas que la reconfiguran, alterando las espacialidades y las funciones, al mismo tiempo que son creadoras de nuevas prácticas. En este artículo se propone una interpretación de las diferentes prácticas en tres barrios de la periferia madrileña en torno a las resistencias, la identidad y los vínculos sobre el territorio, atravesando sus distintas dimensiones, muchas veces frágiles, que van articulando procesos y discursos que constituyen esos mismos barrios. Es en este sentido que entendemos el barrionalismo como una práctica política que re-configura las espacialidades y dota de una identidad discursiva a sus habitantes. Práctica por su noción de ensayo, de re-creación constante y cotidiana. Política en tanto que se conecta con los conflictos que atraviesan los espacios. El programa de investigación en el que se enmarca este artículo aterriza el análisis sistemático de los dos últimos censos disponibles, así como datos complementarios ofrecidos por el padrón, con la observación y el trabajo en los lugares estudiados. Atendiendo a la dimensión simbólica que dota de significante las ciudades queremos continuar el debate sobre la importancia de las estructuras comunitarias, cuáles son las condiciones que se articulan en un espacio y un tiempo concreto vinculando a sus habitantes sobre esos territorios. La narración como una forma de politizar los fenómenos sociales, será el elemento fundamental que hacen de la aproximación metodológica escogida más relevante.

El plan de lectura del artículo compone los epígrafes a partir de los elementos que sistematizamos. Comenzamos con un análisis material de los espacios observados. ¿Cómo influye la forma urbana en las posibilidades de apropiación del espacio y re-creación discursiva? La arquitectura y el planeamiento urbano como discurso en tensión, como tal es leído y está sujeto a re-configuraciones.

El segundo de los epígrafes establece un breve recorrido sobre los movimientos sociales urbanos que han operado en los barrios que hemos analizado, tratando de captar no solo el carácter conflictivo del espacio, sino las alteraciones simbólicas que dichos movimientos producen sobre los lugares.

En el tercer epígrafe elaboramos una propuesta para analizar los lugares entendidos más allá de los espacios, como un depositario de sentidos, afectos, símbolos y temporalidades (TUAN, 1977) sujetos a constantes re-creaciones, y que por lo tanto han de ser observados de un modo dinámico y en relación y conflicto con sus habitantes, donde se establece un juego entre la formación de la identidad espacial, así como la identidad de sus habitantes.

El orden de los epígrafes nos parece asimismo relevante pues es un modo de aproximación que trata de articular una relación en sí mismo. En un primer momento se observa lo material, lo sólido, el espacio continente, en un segundo momento las prácticas, las alteraciones politizadas a partir de ese espacio y en un último momento se observa lo cotidiano, 24 horas que engloban la historia del mundo y la de la sociedad. (LeFEBVRE, 1972). Lo inesperado, las relaciones conflictivas que son constituyentes de ese simbólico que no por ser abstracto, se construye en el aire y que no por ser interpretado ha de carecer de método. Y es ahí, en la intersección de estos tres planos o dimensiones del análisis donde situamos la posibilidad del barrionalismo entendido como una práctica política.

Una última consideración para el debate tiene que ver con la dimensión multiescalar de los espacios. Si los lugares se constituyen también por flujos y procesos de carácter global, ¿de 
qué manera son influidos estos por las prácticas políticas de los lugares? O dicho de otra forma, afirmamos que si la dimensión global de las ciudades no es solo un camino de ida, el barrionalismo como práctica política es también una práctica que altera las geografías globales. De las ciudades como actor global, a los barrios como actor global. $Y$ es en este punto donde consideramos la potencia de nuestro argumento, abriendo un camino para la reflexión donde la agencia, la posibilidad de iniciativa se sitúa en lo próximo, no como resistencia, sino como capacidad cierta de transformación.

\section{De la periferia de Madrid a la centralidad en las periferias. El espacio del barrio}

Los tres espacios analizados comparten características sociodemográficas y espaciales similares. Atravesados por contextos de vulnerabilidad, donde las prácticas de habitar se desarrollan entre el conflicto, la cooperación y la inventiva. Comunidades olvidadas por la iniciativa privada, así como por la administración, abocadas a desarrollar alternativas que garanticen la sostenibilidad de sus vidas. A caballo entre el deseo, la imposibilidad y la proyección de un horizonte que encuentra en los espacios inmediatos imágenes condicionadas por la desesperanza.

Un elemento que comparten los tres espacios, aunque con distintas intensidades es el desdibujamiento de las fronteras entre lo público y lo privado, el barrio y los hogares.

En contextos de vulnerabilidad el apego a un territorio concreto se vuelve mucho más determinante, pues las necesidades de sostenibilidad de la vida están profundamente vinculadas a la ecuación espacio-tiempo. Por un lado, estas se encuentran ancladas al hogar como paradigma espacial de resolución de las necesidades de reproducción, un hogar que al mismo tiempo incorpora los conflictos y ausencias del espacio exterior donde se ubica.

\footnotetext{
${ }^{3}$ Esta información ha sido extraída a partir del trabajo de investigación sobre el terreno. La idea es reproducida por todas las informantes claves entrevistadas en el barrio, incluidos los representantes municipales. Si bien es cierto que no hemos encontrado una referencia escrita sobre este hecho, nos parece relevante incluirlo en el texto pues forma parte de la representación que de su propio barrio hacen los habitantes del mismo. Otro elemento que da veracidad a esta hipótesis son los metros cuadrados de la superficie de las viviendas. Si las superficies mínimas de vivienda de los
}

El espacio estudiado en Alcalá de Henares es el barrio de los Reyes Católicos situado en el Distrito II de la ciudad. Este barrio es fruto de diversas actuaciones urbanísticas siendo la más relevante la que tiene lugar a comienzos de la década de los 70 del pasado siglo donde se edifica el polígono puerta Madrid con una promoción de 1500 viviendas, articulando una morfología urbana con un impacto importante sobre el conjunto del espacio del barrio. En un primer momento estas viviendas se diseñan con el objetivo de ser una promoción destinada a los cuerpos de seguridad del estado ${ }^{3}$, decisión que finalmente no se lleva a cabo y termina por constituirse como un lote de vivienda de promoción social para realojar a personas en situación de vulnerabilidad. Dada la amplia cantidad de viviendas esta población procede desde distintos lugares de la comunidad de Madrid, no es población que habitara, por lo tanto, este espacio con anterioridad.

"Son 1.500 viviendas. (...) Y dos bares, dos farmacias(...) 137 comunidades, 1.564 viviendas." AL6.

Dos elementos destacan de este hecho, el primero de ellos son las calidades y la amplitud de las viviendas, pues son viviendas que oscilan entre los $100 \mathrm{~m}^{2}$ y los $150 \mathrm{~m}^{2}$, donde el trazado urbano se articula en torno a las manzanas semi-cerradas, rodeadas de zonas ajardinadas. Un modo de proceder que como recuerdan Ezquiaga, son formas muy comunes en la edificación de la periferia.(EzQUIAGA, 1990): Este modelo tal y como señala LóPEZ DE LUCıO es de "ensanche fragmento" (CARIES MARTí \& al., 1995) no vinculado a una planificación generalizada del conjunto de la ciudad, es decir, no como parte en relación y con relación a la totalidad de la ciudad y por lo tanto inserto dentro de un mismo proceso urbano, sino relacionada con procesos fragmentarios, parciales y desconectados así de una visión integrada de la ciudad. En el espacio del barrio en concreto, y tal y como apunta Ezquiaga, estos modelos de manzana semi-cerradas están vinculados a la crisis del zócalo comercial, pasando del modelo de "las manzanas centrífugas" que proyectan vitalidad y conexión hacia el resto del espacio, al de

poblados de absorción eran $59 m^{2}$ (ONTAÑón, M. J., \& MoRALES, J. M. L. P.,1971) aumentando hasta los $90 \mathrm{~m}^{2}$ en los poblados dirigidos buscando atraer a las clases medias (RuBıo, M. V., 1974), en el caso de estas viviendas, cuyo tamaño oscila entre los 100 y los $150 \mathrm{~m}^{2}$, máximo permitido para la protección oficial según la legislación de la comunidad de Madrid, nos hace creer que el adjudicatario final de las mismas, población vulnerable, no era el mismo que en el origen del proyecto. 
"manzana centrípeta", expulsora de esta vitalidad exterior. Este opera casi como una frontera urbana en la que se rompen las transiciones entre los espacios privados de los hogares y los públicos donde la propia noción de calle sería el elemento por excelencia de la vida urbana. Se trata, por lo tanto, de un modelo urbano donde las manzanas operarían como islas, en el caso de este barrio de escasas densidades, diseñadas para favorecer el intercambio y el juego de los menores que encontrarían en esos espacios una desconexión con el tráfico o los "peligros de la calle".

Lo que en un primer momento es un diseño pensado en modos de vida vinculados a clases medias adultas - jóvenes con hijos - así lo corroboran tanto el tamaño de las viviendas y su disposición - como el modelo urbano-en el contexto que atraviesa el espacio estudiado, mediado por familias con una fuerte situación de vulnerabilidad y en la actualidad profundamente envejecidas, presenta un espacio urbano muy degradado que multiplica la sensación de dejadez e inseguridad. El estado de las manzanas, Delegado a las comunidades de vecinos, se convierte en una suerte de laberinto trufado de espacios ciegos para el caminante que atraviesa el barrio. Ese modelo urbanístico fragmentario si bien nunca funcionó a escala ciudad, por romper con el arquetipo urbano por excelencia que sería la calle como elemento de diversidad y estructurante de los paisajes urbanos, demuestra sus fracasos una vez se pasa de las definiciones ideales de los planos a lo inesperado de las realidades contextuales de las periferias. Lo que en su día fueron jardineras hoy son papeleras improvisadas que incrementan la sensación de dejadez y abandono de los espacios del barrio lo cual transmite una suerte de falta o pérdida de control por parte de los vecinos juntos con la erosión del sentido comunitario de los mismos (BRown \& al., 2003:260). Además, lo que en algún momento fueron locales de actividades y pequeño comercio de proximidad hoy lucen transformados en viviendas de dudoso régimen legal.

El monocultivo urbano no es un éxito ni cuando cumple sus expectativas para las que fueron proyectadas, la ciudad necesita de una diversidad de actividades, trazados, habitantes e imaginarios para operar como una máquina bien engrasada. Lo contrario es un devenir fragmentario donde en algunos casos hallaremos islas atravesadas por el bienestar, erigidas como espacios infranqueables por el visitantes y, en otros, allá donde la historia de la desindustrialización y las crisis económicas y financieras dejan sus huellas, encontraremos espacios abandonados, envejecidos que van sumando desigualdades y problemáticas conforme el tiempo sigue pasando. Para los habitantes originales, lo que en un principio fue una promesa de un comienzo vinculado a la construcción de un nuevo hogar, deviene en una prisión donde la vivienda ha perdido su valor y por lo tanto no solo la edad sino las posibilidades materiales te atan a ese espacio que cada día reconoces menos. Los precios bajos, si bien suponen un alivio fundamental en el devenir cotidiano, en un modelo fundamentalmente de propietarios como es nuestro país, donde la vivienda ha de interpretarse como un bien patrimonial de garantía de existencia con mayor relevancia en contextos de vulnerabilidad, en este caso, se convierte en una prisión que te ata a este territorio limitando las proyecciones y horizontes de ascenso social.

"Es un barrio envejecido, muy envejecido. Son pisos eran muy baratos, de renta muy barata. Yo creo que se pagaba 2000 pesetas" AL5.

"Mi madre está pagando está pagando 13.(...)porque mi madre no lo ha terminado de pagar y está pagando 13 euros, yo le he dicho que no lo tiene que pagar nada, por 13 euros." AL3.
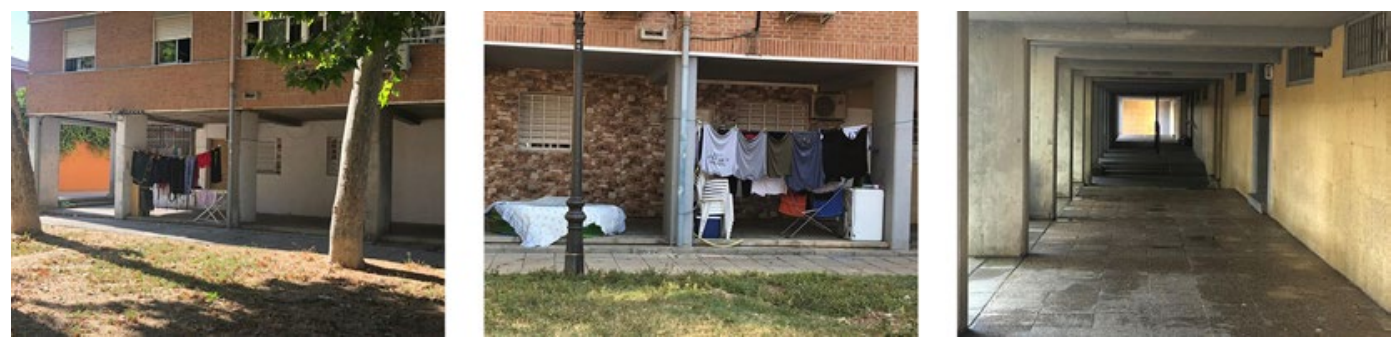

FIGS. 1, 2, y 3 / Imágenes del tipo de Manzanas que componen el barrio de Reyes Católicos.

Fuente: elaboración propia de las autoras. 
Lo que llama la atención de las fotografías que aparecen las FIGS. 1, 2, y 3 es justamente esta ruptura entre el dentro y el afuera. Los soportales que rodean las manzanas - recordamos son suelo privado de uso público, por lo que el mantenimiento de las mismas corresponde a las comunidades mientras que el acceso es libre - acaban funcionando como una extensión de los hogares, operando de facto una apropiación del espacio público de la comunidad para uso privado privativo. La altura de los techos, así como la disposición y el vaciamiento total de cualquier actividad comercial potencian la percepción de inseguridad, proyectando una imagen/discurso de estar adentrándose en una comunidad abigarrada, fragmentada del resto del espacio urbano.

"Está todo más sucio, las calles también están más rotas. Tú cruzas una calle y ya forma parte de lo que es el centro de Alcalá, es que si está al lado." GAL2.

Este uso extensivo del espacio público, como si del propio hogar se tratara, genera rechazo entre las vecinas y vecinos lo que junto con el estado general de abandono y suciedad del entorno (derivado del tipo de tenencia que comentábamos anteriormente que delega su mantenimiento a la responsabilidad de las comunidades) actúa como un fuerte impedimento en los procesos de apropiación comunitaria.

"Lo único que andan así con sus batas, y que los niños lo vean así, que después el día de mañana el niño con 15 años me sale igual a la calle." GAL2.

"Por la noche sacaban la mesita fuera, al lado del piso con las sillas hasta las 5 de la mañana." GAL 2.

El arquitecto urbanista danés Jan GEHL (2006) categoriza en tres las actividades realizadas en los espacios públicos, Actividades necesarias, actividades opcionales, actividades resultantes, correlacionando la frecuencia con la que se producen con la calidad del entorno físico. A través de esta correlación Gehl demuestra la relación positiva entre la calidad del entorno y las actividades opcionales de tal forma que a una calidad alta del primero corresponde un nivel alto de actividades opcionales. Por otro lado, una calidad baja del entorno se relaciona con un nivel bajo de actividades opcionales mientras que el nivel de actividades necesarias parece ser independiente de la calidad del espacio, probablemente por la propia naturaleza de esas actividades. Sobre todo las actividades opcionales, aquellas que tienen que ver con el despliegue de actividades en las "que se participa si existe un deseo de hacerlo o si lo permiten el tiempo y el lugar" (GEHL, 2006: 17), vinculadas a apropiaciones soft del espacio tales como pasear, pasar el rato... que constituyen el paso previo para la re-creación de comunidades estables sobre el territorio, suponiendo la antesala de la transformación del espacio en lugar (MASSEY, 1994), están profundamente influenciadas por la calidad del entorno, así como las actividades sociales.

En el caso de Abrantes observamos problemáticas vinculadas al deterioro del espacio que podrían ser parecidas, una vez más se repite el modelo de espacios interbloques de tenencia privada pero uso público, así como una sensación de abandono y ruptura de los vínculos con la administración que se manifiesta tanto en carencias de equipamientos y baja calidad de los mismos como, en su forma más expresiva, en suciedad.

“...es que en el barrio no teníamos ni un parque
infantil en condiciones, o sea, el parque que está
ahí en este descampado que habréis atravesado
seguramente, ni existía, o sea, es que no había ni
zonas donde los niños pudieran estar. Entonces,
bueno, poco a poco se ha ido mejorando..." A4.

“...bibliotecas aquí en la zona, yo creo que en la zona de Abrantes, no me hagas caso, pero creo que bibliotecas no hay ninguna, creo..." A1.

“...tú ves la suciedad que se acumula en las calles. Jardines, por ejemplo, prácticamente no hay. Juegos para niños tampoco... Entonces es como una isla, porque en esta zona de la Avenida de la Peseta que ya vuelve a ser una zona que supone que está bien, ¿no? Más allá de lo que es los poblados, pero esta zona, sobre todo lo que es la plaza de Pan Bendito, fatal..." A8.

No obstante, el diseño fomenta mucho más la diversidad pues encontramos tipologías de viviendas más mezcladas, fruto también de distintos períodos de urbanización, lo que entre otras cosas da cuenta de un barrio en transformación, lejos del estancamiento del barrio de Reyes Católicos, donde no se ha edificado nada desde aquella promoción de viviendas. En el caso de Abrantes encontramos dos espacialidades diferenciadas: la colonia de Vista Alegre y la Unidad Vecinal de Absorción de Pan Bendito, ambas concebidas con carácter provisional en los años 1957 y 1963, respectivamente.

Dos hechos nos parecen fundamentales, por un lado, estos dos espacios son productos de un desarraigo de población que viene de otros territorios y que por lo tanto no tenía un vínculo sobre este barrio, y por el otro, que su carácter provisional, al menos en inicio, determinó una forma de conciencia sobre el territorio ocupado que mermaba las proyecciones y posibles apropiaciones del mismo. El resto del barrio sufrió nuevamente 
un fuerte crecimiento en la década de los 60 y 70 por una migración interior y como ocurriera en otros distritos de la capital estas ocupaciones se concretan en el programa de remodelación de barrios de los ochenta realizado por el Instituto Nacional de Vivienda, donde se realojan esas colonias de migración interna. A partir de la década de los 2000 veríamos otro gran proceso de mudanza dentro del barrio, las hijas e hijos de las familias pobladoras, fruto del proceso de ascenso social generalizado en nuestro país, cambian de barrio y su lugar viene a ser ocupado por migración exterior, fundamentalmente de América Latina y de Marruecos. El resultante del barrio, si bien atravesado por procesos de vulnerabilidad, es una diversidad y un dinamismo que contrastan con el espacio antes observado.

El diseño, las proyecciones sobre el horizonte espacial, así como la diversidad en los habitantes, constituyen al barrio de Abrantes en una forma espacial que permite la recreación de tipos comunitarios y ocupaciones territoriales con horizontes más vinculados a la dinámica conjunta de la ciudad. Diversidad, por lo tanto, en el diseño, en los pobladores y en las temporalidades serían elementos fundamentales en la recreación del barrio.

En las imágenes podemos observar diferentes tipologías de vivienda, así como la ausencia de locales comerciales.

Las FIGs. 4, 5 y 6 ilustran distintas tipologías de viviendas, aunque también persiste la ausencia de locales comerciales, lo que desde el punto de vista de la recreación y la producción de la vida comunitaria afecta. No obstante, nos parecería un ejemplo de diseño a caballo entre el estancamiento del barrio de Reyes Católicos y el mayor dinamismo de Entrevías.

Desde el punto de vista analítico que proponíamos como cruce entre el hogar, la familia, el empleo y las redes comunitarias, entendidas estas no solo como instituciones esenciales en los procesos de sostenibilidad de la vida, sino sobre todo, y por lo que a este artículo toca, como espacialidades distintas pero conectadas, de lo que se trataría es de establecer los vínculos espacio-temporales. El concepto de cotidianidad de LEFEBVRE (1972) es certero y sería el inspirador de esta propuesta. Lo relevante del análisis no es comprender cada una de ellas de forma fragmentada, sino poner el acento en los nexos de conexión, los encadenamientos que operan en cada una de estas facetas, de tal forma que apreciemos el protagonismo del territorio no como soporte sino como productor de dichos encadenamientos. De ahí la importancia en la comprensión del diseño, el tipo de poblador, así como los equipamientos y las posibilidades de empleo.

Por otro lado, en el caso del barrio de Entrevías las dinámicas espaciales se ven influidas tanto por el mismo trazado como por las fronteras urbanas. Entrevías se encuentra rodeado por barreras y límites físicos-urbanísticos: la vía del tren, la M30 y el parque forestal suponen:

"fronteras físicas resistentes, los límites, los espacios y la arquitectura del barrio ponen límites a las acciones y a los movimientos y por ende al alcance de la ciudad" (PASQUI, 2008: 83)

por parte de los vecinos del barrio. Estas barreras desincentivaron a lo largo de los años la salida del "enclave duramente conquistado" (SMALL, 2011: 107), favoreciendo entonces costumbres y rutinas barriales que fortalecieron la apropiación y la territorialización (DELEUZE \& PARNET, 1998) del espacio barrial.

Además, este aislamiento supuso la necesidad de instalar un abanico de servicios diversificados dentro del espacio del barrio. En la zona central hay una comisaría, una galería comercial, unos cuantos pequeños comercios de diferente tipo mientras que en el territorio del barrio dos centros de salud, dos centros de mayores y un centro cultural. A pesar de que los vecinos
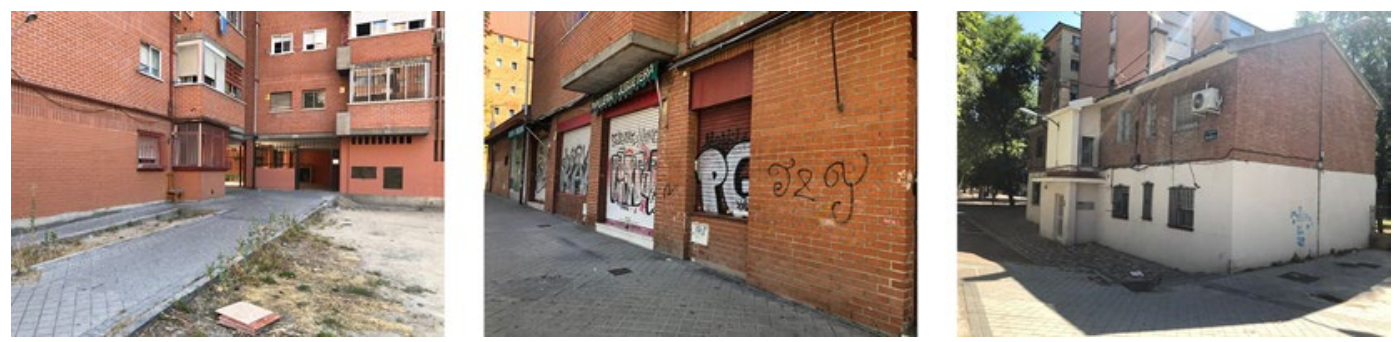

FIGS. 4, 5, y 6 / distintas tipologías de viviendas.

Fuente: elaboración propia de las autoras. 


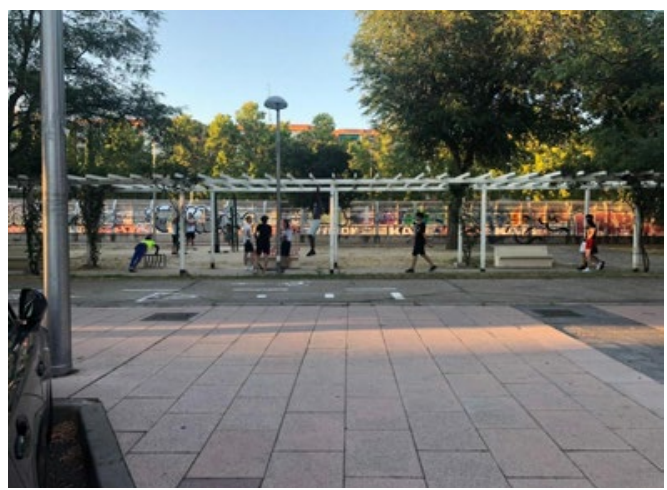

FIG. 7/ Escenas cotidianas de re-creación comunitaria alrededor de las vías del tren.

Fuente: elaboración propia de las autoras.

lamenten la calidad y la falta de servicios, en comparación con los barrios de Abrantes y de Reyes Católicos, el barrio de Entrevías está mejor equipado tanto en infraestructuras como en diversidad de los servicios presentes. La presencia de comercios y de servicios resulta fundamental para poder desarrollar todo tipo de actividades necesarias (GEHL, 2006) y si bien ligadas a las necesidades, muchas rutinas y prácticas espaciales de los vecinos se materializan en el espacio del barrio. De esta manera aumentan las posibilidades de interacción tanto entre personas como entre individuos y espacios influyendo sobre el placemaking de los

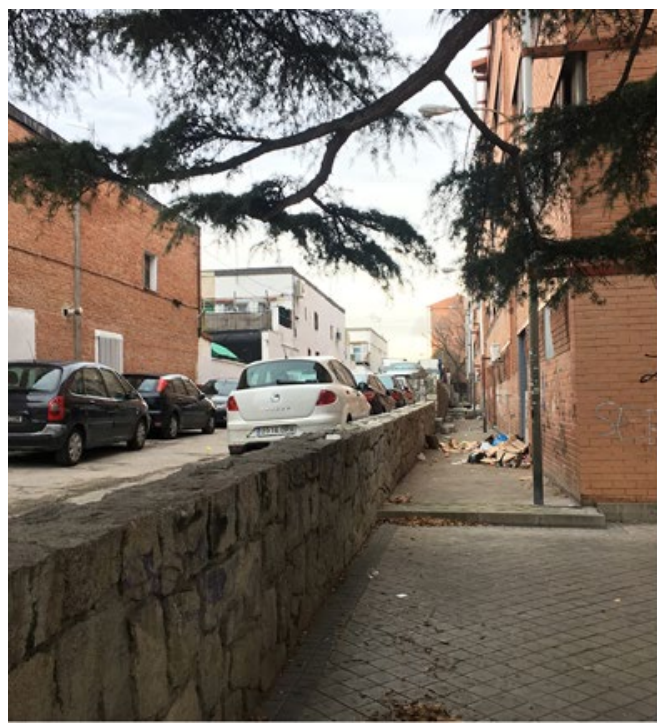

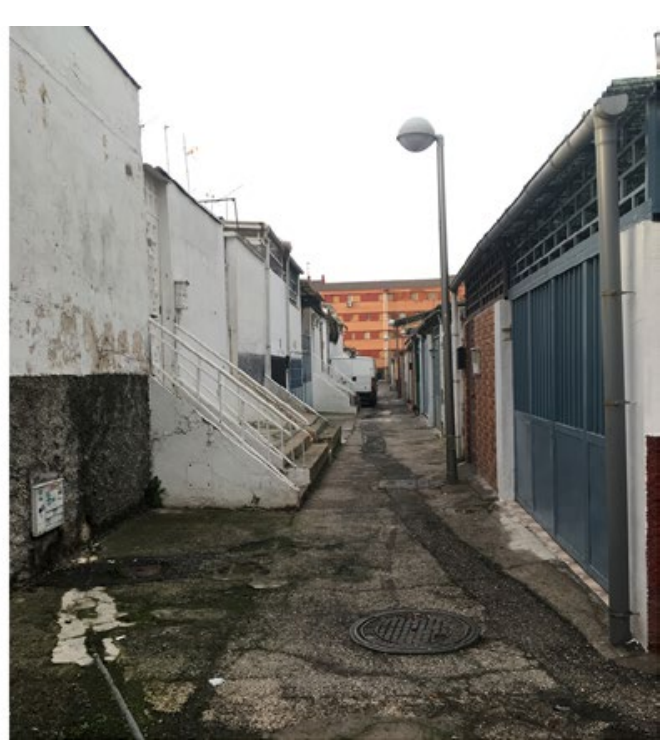

vecinos: un barrio con carencias de todo tipo de servicios, que no ofrece nada y obliga al desplazamiento para el desarrollo de cualquier actividad, no es un barrio en el que los residentes quisieran quedarse a vivir.

Por otro lado, el diseño urbano de Entrevías se caracteriza por algunos elementos peculiares. Como en el caso de Abrantes, encontramos diferentes tipos de viviendas mezcladas que crean espacios y calles con un horizonte más o menos abierto. Este elemento influye sobre las diferentes prácticas de apropiación de los diferentes colectivos y es fundamental para aproximarse a las perspectivas y visiones del espacio de los vecinos.

El diseño preveía, entre bloques o entre manzanas, plazas y zonas de juego infantil, espacios donde las comunidades de vecinos pudiesen reunirse y estar. Sin embargo, estas, se encuentran enclaustrada, en su mayoría, en edificios impidiendo de esta manera una amplia visual sobre el espacio a aquellos que lo atraviesen.

"O sea, durante el día pues yo ningún problema, pero con la noche algunas zonas también por... como están... como por, por el trazado, ¿no?, el tema de... casitas bajas con plazas en el medio, placitas entre bloques desangeladas, o sea sí como... y luego como un parque gigante oscuro... un parque forestal alrededor..." E3.

Quienes habitan el barrio lamentan entonces inseguridad y suciedad en el espacio público,

FIGS. 8 y 9 / Espacios de Entrevías. 
los vecinos hablan de descuido, de desinterés tanto por parte de las administraciones como por parte de los demás vecinos. El desinterés de los demás se materializa en el espacio a través de una "apropiación ilegítima" y de la suciedad. Esta ilegitimidad se expresa de forma reflexiva, eso es, parte de la población siente "negado su derecho a la apropiación del espacio" (DACONTO, 2014: 35). Sensación que frustra a los vecinos y por la cual llegan a desarrollar cierto rechazo hacia el espacio público de su propio barrio.

“...del espacio público, eh de... problemáticas asociadas a ruidos... sobre todo es por la apropiación de, del uso del espacio público. O sea, tú plantas una barbacoa en medio y es como, vale, pa', pa'... pa' ti y pa' tus colegas perfecto, pero, ¿no?, como que todo eso se queda... se queda lleno de carbón, de mierda, huele fatal... ¿no?, es como..." E3.

"No, no, no, hay mucha porquería. Mucha porquería. Ya le digo... de hojas de barro de agua, de cacas de los perros de la gente que va y tira la basura fuera cuando..." E1.

Lo que más diferencia Entrevías de los otros dos barrios es la presencia de espacios públicos conocidos, reconocidos y utilizados por parte de los vecinos. En concreto: El Parque Forestal de Entrevías y la estación Asamblea de Madrid, donde, después de la reforma, se instalaron parques biosaludables para mayores, un barco pirata para los niños, y una plaza con bancos que cualquier vecino podría ocupar. Estos lugares gozan de la característica del active engagment (CARR, 2012) son lugares interesantes, entretenidos, óptimos para el desarrollo de las actividades opcionales (GEHL, 2006). Aquí se puede observar cierta coherencia entre las tres dimensiones lefebverianas del espacio y como consecuencia estos sitios se vuelven en lugares, aptos para la socialización, reconocidos y conocidos por la población, puntos de encuentro donde se crea y se refuerza la identidad del barrio. Su posición céntrica en el territorio del barrio además ha facilitado y facilita la rutinización (DACONTO, 2014) de las actividades desarrolladas en ellos, fortaleciendo por ello costumbres e identidades barriales.

"Hay placitas, sí. Pues en el verano, en el invierno menos, pero en el verano si, si, si, sí. La gente sale mucho. Está ahí, si...Hay vida de calles, niños... sí. Se nota... se nota que es una de las cosas que... que te apega más al barrio, que no te deja ir. O sea esa..." E9.

Como podemos observar en los ejemplos de las FIGs. 7, 8, 9 y 10, el espacio de Entrevías es el más diversificado y territorializado de los tres

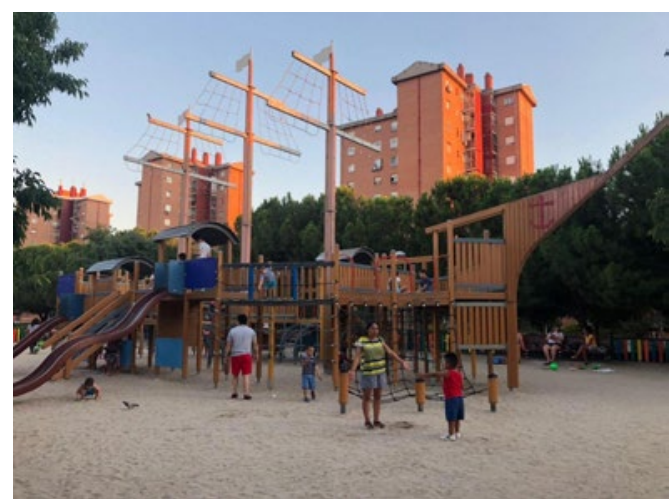

FIG. 10/ Espacio de Entrevías.

Fuente: las autoras.

barrios analizados, quizás por su historia o su recorrido, aquí los vínculos espacio-temporales ligados a las proyecciones futuras y desarrollados a lo largo del tiempo, lograron la conquista de los hogares, han permitido el desarrollo de este apego e identidad de barrio.

\section{Los movimientos sociales urbanos en la producción del barrio}

La construcción del espacio y de la identidad en los barrios marginales de la ciudad de Madrid, pasó, en los años 50-60 por las luchas vecinales. Estos movimientos, por aquel entonces ilegales como todos movimientos, consiguieron desplegar una densa red organizativa tanto al interno de los mismos como en cooperación con otros movimientos de protesta y reivindicación.

"Cualquiera sea su futuro su pasado ya ha hecho historia" escribió CASTELLS (1977: 97) y en un análisis de las identidades barriales resulta imprescindible preguntarse sobre la importancia que estas asociaciones de vecinos tuvieron en la construcción material, moral e ideal del barrio, la huella que dejaron y el papel que tienen hoy en día en los territorios que las vieron nacer.

Para empezar, hay que destacar que en barrios como Entrevías los relatos de vecinos de diferentes generaciones nombran dichas asociaciones, todos las conocen, son conscientes de sus logros y de la importancia que tuvieron. Los mayores, la primera generación de vecinos de estos barrios, recuerdan su pasado chabolistas y las luchas por una vivienda digna, "El barrio lo construimos nosotros", los adultos y los jóvenes, criados en un contexto diferente, si bien conscientes de la historia, ligan las AA. VV 
(asociaciones de vecinos) a lo que sería la construcción del barrio a través de las costumbres barriales (MARGULIS, 2002) más que por los logros materiales.

Sin embargo, a pesar del acuerdo más o menos generalizado sobre su importancia, hoy en día las AAVV tienen una posición, dentro del tejido asociativo del barrio, y una presencia en el territorio que se ha quedado básicamente residual. Los pocos miembros lamentan la falta de interés por parte de la población joven, no participan ni están comprometidos con el barrio, no les importa de su territorio, se dedican a otras cosas

“...a los jóvenes de hoy en dia na'mas que les interesan los i phones y la cerveza "E8.

"La Asociación con el conjunto de muchos vecinos, no como ahora. Que ahora no quieren saber nada. Pero entonces los vecinos sí querían." E1

Nuestra aproximación no pretende hacer un análisis profundo sobre los movimientos sociales urbanos de estos barrios si no tratar de entender cómo su evolución a lo largo de los años y su desaparición puede haber influido en las identidades y relatos barriales.

Es importante delinear el recorrido histórico de las AAVV para matizar y entender las diferentes evoluciones que vivieron a lo largo de estos años los tres barrios analizados. Las diferencias de contextos, logros, poder de negociación del que gozaron en su día han ido plasmando de forma diferente la idea, el relato y la identidad del barrio y como consecuencia el compromiso, el interés y la participación en el territorio.

Entrevías, entre los años ‘40-'50, fue destino de las olas migratorias de la Mancha, Extremadura y Andalucía, allí los recién llegados a Madrid pudieron y decidieron instalarse, haciendo de ese terreno-territorio-barrio una zona chabolista. Las pésimas condiciones sanitarias, las movilizaciones vecinales y las presiones de las clases media y alta, además de la estrategia política de la dictadura franquista de esa época, llevaron a la construcción de casas y bloques para realojar a la población del barrio (CASTELLS, 1977). En Entrevías se intentó aplicar el criterio de no desterritorialización, por lo que la población que ocuparía las viviendas en los poblados ya vivía anteriormente en el barrio.

En el barro de Entrevías los movimientos vecinales encontraron un terreno muy fértil y los logros obtenidos les dieron fuerza y poder para seguir en su lucha por la obtención de logros materiales, concretados en más viviendas y más y mejores infraestructuras.
Por otro lado, Abrantes, territorio de chabolas como Entrevías, vivió un proceso de realojo de población en situación desfavorecida y de exclusión, totalmente diferente. En ese territorio fueron, de hecho, realojadas personas provenientes de diferentes asentamientos chabolistas de la ciudad de Madrid, conllevando una concentración de familias en condición precaria que no habían tenido un pasado en común. Además, la fundación de la asociación de vecinos de Pan Bendito, una de las colonias de realojo del barrio de Abrantes, se produce en el año 81 , en un contexto, por lo tanto, muy diferente con respecto a Entrevías. Los jóvenes no conocen esta asociación, para los residentes no resulta un punto de referencia y en la actualidad el local, sede de la asociación, aparece cerrado y el número de teléfono de la misma desactivado.

Finalmente, el proyecto de VPO (Viviendas de Protección Oficial) de Alcalá de Henares estaba destinado a trabajadores del ejército y a funcionarios del mismo, detalle que explica la calidad y el tamaño de los pisos (entre 100 y $150 \mathrm{~m}^{2}$ ). Todos los bajos de esos bloques, que estaban destinados al pequeño comercio de barrio, se convirtieron en viviendas ocupadas por población vulnerable.

"No quisieron, no quisieron. Mis padres cuando compraron el piso hace muchísimos años, le dijeron que este era un bloque de militares, pero los militares no querían venirse a las afueras de Alcalá y les dieron unos que hay en San Isidro. En la estación de Servicio de San Isidro hay algunos bloques de militares que son ahora."AL5.

"Se hizo inicialmente, dijeron, bueno esto era un, un búnquer para militares, para familias militares, y como en aquel tiempo, solamente pasaba la Nacional 2..." AL4.

Sin embargo, la asociación de vecinos a pesar de no estar ligada a la lucha por una vivienda digna, por un hogar en definitiva, consiguió encontrar su espacio y dimensión dentro de las dinámicas barriales. Los vecinos la reconocen como punto de referencia y tiene cierto papel de puente y de negociación entre los vecinos y sus necesidades, y la administración del Ayuntamiento de Alcalá. Además, el tejido asociativo del barrio se caracteriza por la presencia del colectivo CAJE (Colectivo de Acción para el Juego y la Educación) que comienza desarrollando un trabajo fundamentalmente con niños, niñas y adolescentes en situación de vulnerabilidad, a partir del cual irá desarrollando más actividades y talleres con un público objetivo más amplio, tales como talleres de alfabetización para adultos y actividades de carácter lúdico. Otra de las 
características del colectivo que resaltan su fortaleza y el vínculo con el barrio es el modelo de formación de las personas voluntarias que pretende vincular a las jóvenes que aterrizan en el colectivo para recibir apoyo al colectivo como futuros voluntarios. Establece así apegos más estables, transformando un primer momento asistencial en un posicionamiento de la agencia, empoderando a las jóvenes y haciéndolas parte del proyecto del colectivo. CAJE es, de este modo, un referente social reconocido en el conjunto del barrio, atendiendo a dinámicas comunitarias no tan ancladas en lo material o las resistencias de carácter más político, como con actividades más vinculadas a los cuidados y a una visión de comunidad afectiva.

Este recorrido histórico de las AAVV de los tres barrios analizados, independientemente de las evidencias estadísticas o de la escasa participación en las AAVV por parte de la población, se refleja en los relatos de los vecinos sobre su propio barrio y sobre su propia identidad.

En Entrevías la primera generación de vecinos fue, con el tiempo, creando un propio barrio de chabolas, con su organización interna, sus calles y sus dinámicas. La situación socio-económica de los vecinos era parecida, tuvieron que luchar por las mejoras, la necesidad más que la voluntad política hizo posible la organización de un movimiento fuerte y compacto. Sucesivamente, los vecinos que llegaron en un segundo momento, a pesar de no tener una conexión generacional (MANNHEIM, 1998) con los demás, pertenecían a la misma generación y compartían con ellos una afinidad cultural, normativa, moral y político-social (MANNHEIM, 1998), y se encontraron un tejido asociativo y reivindicativo fuerte, capaz de lograr mejoras para el territorio, en definitiva, Entrevías era un barrio donde se materializaba la promesa de ascenso social. Paseando por las calles de Entrevías se pueden encontrar placas conmemorativas de esas conquistas y los nombres de las calles son los nombres de los pueblos de proveniencia de los ex chabolistas. El lenguaje del barrio, lo que comunica a sus residentes y a quienes lo atraviesen (MARGULIS, 2002) es un lenguaje de conquista, cada rincón conquistado del barrio acabó llevando consigo tanto el pasado como el presente y futuro de esta nueva población.

Además, la presencia de estos elementos es fundamental para el mantenimiento de la identidad, esta necesita cierta continuidad que viene de la interacción con el ambiente y los espacios los cuales, en este sentido, la perpetúan y reproducen (Wester-HeRBER, 2004: 112).
La identidad reivindicativa de Vallekas encuentra en Entrevías un ejemplo perfecto de su materialización territorial y lingüística en los relatos de la población.

En Abrantes, por otro lado, la asociación de Pan Bendito se constituyó muchos años después del primer realojo, en un contexto social, político e histórico totalmente diferente como diferentes eran las necesidades de aquella población del barrio. Estas diferencias se materializaron en un acercamiento a los residentes cuyas problemáticas eran la pobreza, la falta de trabajo y la drogadicción, se instaló entonces en el barrio con un espíritu menos reivindicativo y más asistencialista quizás. Estas ayudas y ese enfoque no fueron capaces de plasmar una identidad barrial, la diferencia quizás esté entre sobrevivir y ser. Si bien en algunas entrevistas se habla de solidaridad y cercanía entre vecinos, este apoyo no se vincula al ser de Abrantes, no se vincula a una historia de logros, resistencia y resiliencia. Abrantes, según los vecinos entrevistados, no es un barrio que se pueda rescatar a sí mismo, no tiene esa fuerza interna de la que se habla en Entrevías, necesita una limpieza, una intervención externa. El tejido asociativo se describe como "frágil" por los entrevistados. Esta falta de una "memoria colectiva" conformada por la "objetividad de los hechos y el interés de los individuos y protagonistas de cambiar la historia" (SchUMANN \& ScotT, 1989: 361) es evidente porque casi nadie conoce la asociación de vecinos de Pan Bendito, por lo tanto, resulta difícil vincular la identidad del barrio a unas luchas concretas o a una solidaridad de ese tipo. El carácter asistencial que planteábamos en líneas precedentes se articula en modelos de intervención actuales, vinculados al esquema de organización del tercer sector no compuesta por activistas asociados a los procesos barriales, sino por trabajadores pertenecientes a organizaciones de carácter social. Estas organizaciones atienden situaciones de emergencia derivadas del colapso de los servicios sociales públicos, pero no hacen parte de formas de auto-organización o de resistencia como pueden ser las asociaciones de vecinos. Este sería el ejemplo de REDES cuya labor es fundamental en el barrio, pero no se constituyen como una asociación de activistas.

Finalmente, Alcalá contiene un proceso singular. Por un lado, el diseño y planeamiento del barrio, que se comentaba en párrafos anteriores y por otro, las demandas de la población más articuladas a partir "de otras dinámicas generales que sobrepasan los límites urbanos pero que se expresan con mayor intensidad en las 
ciudades" (SUBIRATS, 2015: 96). Lo cual puede devenir en organizaciones socio comunitarias un tanto menos ancladas a la cuestión territorial o, al menos con trayectorias que se expresan de forma diferente sobre el territorio.

Las AAVV fueron producto de la época de expansión de las ciudades, en palabras de Castells era un "Movimiento social no clasista que desafiaba la estructura de una sociedad de clases" (CASTELLS, 1992). impulsada por la clase media y por personas en situación de desventaja, recién llegadas a la capital huyendo de la extrema pobreza y en algunos casos la persecución política de la España rural y que se toparon con una realidad que les obligó a vivir en chabolas, donde los procesos de solidaridad y apoyo mutuo se convirtieron en necesarios para la sostenibilidad de sus vidas.

"Un barrio es más que una aglomeración de viviendas (...) la práctica enseña rápidamente a los madrileños periféricos que un barrio no se reduce a una casa donde vivir. $Y$ que se necesitan escuelas, dispensarios, comercio, transportes, jardines, etc." (CASTELLS, 1977: 138).

Su lucha se ligó a sus necesidades sin embargo incluso donde tuvieron un papel relevante, como en Entrevías poco a poco fueron desapareciendo o perdiendo su relevancia. Si la primera generación de dichos barrios se encontró en la obligación de hacer algo para mejorar sus condiciones, los éxitos materiales y la transformación social lograda por ellos creó las condiciones para que sus hijos e hijas, no se vieran obligados a la lucha y a la organización para asegurar la subsistencia.

Este cambio generacional marcado por el "abandono de lo que ya no se necesitaba y el deseo de lo que todavía no se había logrado" (MANHEIMM, 1998: 344) transformó la lucha: ya no era necesario luchar por el territorio pero lo que sí que había que hacer era cuidar los logros de ese territorio conquistado.

La segunda generación, una vez alcanzaron cierta movilidad social, decidieron irse del barrio, a las afueras o a barrios considerados mejores. Este movimiento provocó un cambio poblacional, los vecinos de toda la vida fueron poco a poco reemplazados por los recién llegados y desde los años 2000 en adelante el porcentaje de población migrante, antes irrelevante, fue tomando cada vez más importancia. Este cambio poblacional no explica nada de por sí, sin embargo, es cierto, que los nuevos vecinos no pertenecían a la historia del barrio y no compartían la memoria colectiva que otorgaba cierto tipo de identidad a sus pobladores.

\begin{abstract}
"Lo que pasa que, en el barrio nuestro, en un principio primero sí había muchísima gente joven. Pero la gente joven se fue casando se fue marchando del barrio, y aquí nos hemos quedado pues todas las personas mayores. Están viniendo gente de fuera... pero esa gente de fuera no... no se integra." E1.
\end{abstract}

Este cambio poblacional, además, se vio acompañado por la incorporación masiva de las mujeres al mercado laboral lo que implicó un abandono de la presencia constante que hasta ese momento tenían en los barrios. Sebastian BALFOUR (1994) nos hablará de la "naturaleza matriarcal" de los movimientos de vecinos, dando cuenta no solo de la presencia sino también de las formas de resistencias que estas protagonizaron. En línea con Giuliana de Febo e Ivan Bordetas:

"El barrio representó uno de esos espacios, allí donde se pudieron tejer aquellas redes solidarias entre mujeres que se encuentran en la emergencia de la agitación social y de una toma de conciencia antifranquista" (BORDETAS, 2017: 17).

Las mujeres eran una fuente de socialización y de ocupación del espacio tanto público como privado, la línea de demarcación entre el hogar y la calle se difuminaba, eran una presencia constante en el barrio, eyes on the street (JACOBS, 2011) y capaces de un tipo de organización colectiva necesaria a la vez que identitaria. El análisis de las relaciones de género no da cuenta únicamente de las presencias o ausencias, sino de cómo esas estrategias de despliegue territorial se estructuran a partir de la lógica de la división sexual del trabajo, donde las tareas de cuidados y sostenibilidad de la vida se reifican como elementos vinculados al carácter genérico de la sociedad. Desde este punto de vista la escala de barrio, entendida como espacialidad intermedia entre los hogares y la escalaridad ciudad/fábrica se consolida como eje atravesado por las necesidades de reproducción, por lo que el despliegue de estrategias feminizadas de sostenimiento y mejora de las necesidades vitales se conforman de manera casi natural. Estos elementos además de una asunción de responsabilidades implican una politización concreta de la vida cotidiana, una exigencia de derechos tales como infraestructuras, viviendas... Vinculados al desarrollo de estas obligaciones de cuidado (KAPLAN, 1999).

Las asociaciones de vecinos, antes necesarias y protegidas se encontraron en una situación radicalmente diferente y en contacto con una sociedad lejana en valores, costumbres y necesidades de la que las había creado, tuvieron pues dificultad a la hora de sobrevivir. La población que todavía recuerda con añoranza y cariño 
lo que fueron estas asociaciones es ahora una población envejecida que no participa o participa de forma residual en las actividades de las AAVV. Los cambios operados en la estructura socio-política y económica del país tienen a su vez consecuencia en las formas de resistencia y auto-organización. En el caso de las asociaciones de vecinos este hecho es muy manifiesto. La presencia y la capacidad política en términos no solo de alteración de las agendas políticas sino también de captación de activistas, así como de influencia en tanto que agentes de socialización ha quedado muy limitada. Si durante las décadas anteriores se constituyeron no solo como espacios de resistencia sino como el sujeto de cambio de los barrios, hoy en día mantienen una presencia activa en las esferas de la vida cotidiana de los barrios pero tienen fuertes dificultades a la hora de garantizar su relevo generacional. $Y$ aunque pueda permanecer un ideal de barrio y una identidad barrial ligada a la solidaridad y a la resistencia frente las adversidades ésta está destinada a mutar como ha estado mutando a lo largo de los años. La identidad ligada a los MSU se vincula a la visión de un barrio hogar, un sitio donde merece la pena vivir a pesar de todo, un lugar atravesado y vivido por vecinos que tienen interés en sacarlo adelante lo mejor que puedan.

El tema generacional es aquí fundamental para entender el legado de las AA VV y lo que hay ahora en esos barrios porque las evidencias de las entrevistas sugieren que a trayectorias diferentes se corresponden articulaciones políticas diferentes. En este sentido, las definiciones de MSU de Castell, siguen completamente vigentes, si bien su valor-forma ya no es tanto la de asociaciones de vecinos, sino otros formas de articulación más reticulares y aunque vinculadas al territorio, son legibles en relación con dinámicas que las trascienden.

Debido a estos factores el análisis de los espacios de resistencia y solidaridad de los barrios no puede limitarse a estas organizaciones y como elemento analítico de demarcación se tomó la emergencia del 15 como momento de impugnación (ERREJóN GALVÁN, 2011). e imaginación política que abrió el abanico a nuevas formas de resistencias. En este estudio hemos indagado sobre el impacto en la formación identitaria de las nuevas formas de organización política vinculadas al contexto del 15M que, en las fases posteriores a la okupación de la Puerta del Sol, se descentralizaron en las asambleas de barrios (PASTOR, 2012).

Sin embargo, debemos constatar que, si bien esas asambleas han podido funcionar en otros lugares, en los tres casos estudiados y para el periodo del trabajo de campo, su presencia, en el en los distritos de Vallecas y de Carabanchel, donde se ubican el barrio de Entrevías y el de Abrantes, respectivamente, no se vinculaba a problemáticas concretas del barrio como a planteamientos de carácter más general o si se prefiere sistémico.

Las propuestas no llegan a aterrizarse en formas materiales, las luchas tampoco, las poblaciones más vulnerables no pueden permitirse ser activistas a tiempo completo ni mucho menos estar acampados durante días (CASTELLS, 2012). El movimiento del 15M llegó a tocar esta generación, a impactar sobre su manera de pensar, sin embargo, a pesar de la creación de las asambleas de distrito cuyo fin era acercarse a todos aquellos que no pudiesen ir a la Puerta del Sol, no llegó a aterrizar en el territorio como fuente de cambio.

No se creó en dichos barrios una generación $15 \mathrm{M}$ que luchase por su territorio. Lo que sin embargo sí ha demostrado tener una vigencia relevante y continúa siendo bastante activo en las realidades de Abrantes y Entrevías es la PAH (Plataforma afectados por la hipoteca), hecho, que interpretamos por su fuerte vínculo sobre el espacio y al interno de los barrios. Pues se trata de articular prácticas de resistencia que reconstruyen el vínculo político entre los hogares y el barrio. Conectando al mismo tiempo, con el legado histórico de la labor que desempeñaron las asociaciones de vecinos en el momento de su fundación.

Al mismo tiempo que están:

"siendo capaz, junto con los logros concretos
cambiar la agenda de la política de vivienda apor-
tando una nueva conceptualización del tema"
(IGLESIAS, GARCíA, 2015: 347).

En el caso de Entrevías algunos de los vecinos entrevistados señalan la presencia de la PAH y de las asociaciones que luchan contra los desahucios como una marca identitaria de solidaridad dentro del barrio:

\footnotetext{
"No pero aquí siempre que pasa por ejemplo lo de los desahucios y eso si que es verdad que mucha gente sale." E12.
}

Ahora mismo en los barrios en análisis las realidades asociativas que tienen más poder y relevancia son en Entrevías la Parroquia de San Carlos Borromeo, las AA. VV, Movimiento por la Paz y hay un movimiento alrededor de la casa de la calle Peironcely 10. En Abrantes hay una asociación vinculada a los servicios sociales, REDES. En Alcalá no ha cambiado mucho la situación, la Asociación de Vecinos (AV) Cervantes 
y CAJE. Estas asociaciones están bien arraigadas y en el territorio, todo el mundo las conoce y generan una idea de barrio que se preocupa por si mismo, un barrio donde no vas a estar solo. Estas asociaciones, conforman parte de la identidad de los residentes, aunque sea de forma diferente a las AAVV en su día. Sin embargo, siguen representando un punto de referencia para la socialización de los vecinos del barrio. La diferencia entre Entrevías Alcalá y Abrantes es probablemente que en este último, las asociaciones son más bien de tipo asistencialista. Dan soporte material y psicológico, pero no son lugares de encuentro entre pares que desean vivir y compartir el barrio, se basan en relaciones jerárquicas que ponen cierta distancia entre quien proporciona el servicio y el usuario dificultando así la creación de una identidad alrededor de la misma.

\section{Lugares con identidad, lugares de identidad. El barrio como depósito de prácticas y sentidos}

En los epígrafes anteriores hemos tratado de re-construir una imagen descriptiva del barrio a partir de las referencias espaciales, fundamentalmente vinculadas al trazado y diseño urbano como geografía material concreta. El otro elemento que nos parece fundamental en la construcción imaginativa de los espacios tiene que ver con los movimientos sociales urbanos en tanto que constitutivos de las propias condiciones materiales del barrio como de las imágenes discursivas. En un juego constante entre lo material y lo simbólico, lo significante y lo afectivo los espacios se van dotando de sentido, transformándose por ello en lugares. Desde este punto de vista y como nos recuerda TUAN (1974) los lugares se hacen inteligibles a partir de las significaciones y de las acciones intencionales, sociales y políticas que la gente despliega sobre los mismos, otorgándoles un sentido, siempre en tránsito, no fijado, que sedimenta una serie de significados que van formando dichas espacialidades. En esta operación es indispensable comprender las concatenaciones entre lo temporal y lo físico, nuevamente el papel de la vida cotidiana también como proceso de ordenación de los lugares, no el único, pero sí el fundamental para los procesos de apropiación de dichos espacios, "cuando el espacio nos resulta familiar, se ha convertido en "lugar"(TUAN, 1974: 73).

Sin embargo, esta familiaridad, lejos de ser estática, varía en el espacio/tiempo, Kevin LYNCH (1960) habla de la legibilidad de los espacios como un cruce entre las señales físicas, los elementos espaciales que permiten conocer los patrones de orientación de los lugares, y las emociones y expresiones aspiracionales de sus habitantes en un marco temporal que involucra representaciones sobre el pasado, proyecciones del presente y deseos hacia el futuro.

Es en este sentido que los movimientos sociales urbanos y las sedimentaciones de estos sobre los espacios confieren significados concretos. Incluso si estos movimientos no se transforman en intervenciones físico materiales, tales como lugares concretamente reconocidos, los discursos en torno a ellos acaban por conformar realidades a veces tan sólidas como si de representaciones materiales se tratase.

\begin{abstract}
“...es un símbolo es un símbolo. Vallecas adolece en momento determinado de símbolos en positivo vale y entonces hay una serie... obus, eh, una serie de grupos cañeros de los 80 , el propio rayo... no hay otra identidad, el Atleti y el Madrid son de Madrid, ¿vale? pero el rayo es de Vallecas. el rayo es de Vallecas, entonces eh... si que la gente tiene... el vallecano es muy orgulloso. muy trabajador y muy orgulloso y orgullosa y... de el mismo de su barrio y lo... y lo defiende." E2.
\end{abstract}

En otra línea también tenida en cuenta en la aproximación al concepto del lugar y su importancia en la conformación de las identidades que se vinculan a ellos, Doreen MASSEY (1994), llama la atención a las conexiones más allá de esos lugares, cómo esas identidades, o esos sentidos del lugar se conectan globalmente formando parte de procesos que van más allá de las espacialidades cerradas, son por tanto fluidos y están sujetos a una disputa permanente con elementos que operan más allá de las fronteras delimitadas.

“(...) como por ejemplo hay un caso, que es paradigmático, que es Lavapiés, ¿vale? En el barrio de Lavapiés los alquileres se han multiplicado, se han producido incrementos del $40 \%$. La población tradicional de Lavapiés se estaba desplazando a Carabanchel, a Vallecas. al Puente de Vallecas..." A2.

El barrio como lugar, entendido desde esta triple aproximación. está sujeto de esta manera a una transformación permanente, al mismo tiempo que depósito de temporalidades y prácticas de largo alcance. Las dimensiones pasadas conectan con el presente y se proyectan hacia el futuro aunque tal y como nos recuerda Merrifield:

"Al mismo tiempo, lugar es más que la simple vida cotidiana vivida. Es el "momento" en que lo concebido, lo percibido y lo vivido adquieren una cierta "coherencia estructurada" (MERRIFIELD, 1993:525). 
"Así que el lugar contextualiza y arraiga a las conceptualizaciones lefebvrianas (lo concebido, percibido, vivido)." (OSLENDER, 2002).

El barrio como significante evocado es una constante a lo largo de todo el trabajo de campo. Las personas entrevistadas proyectan en este sentido una serie de aspiraciones, afectos y emociones sobre el lugar que se recogen bajo la idea de barrio. Para dar cuenta de ellas recogemos la propuesta de Per GuSTAFSON (2001) que basándose en el enfoque de la Grounded Theory, elabora un marco de análisis ordenando los significados según se ubiquen más o menos cercanos a los polos Yo, Otros y Entorno, como forma de componer los significados que se condensan en la idea de lugar. Se trata de una propuesta triangular en la que se van ubicando las diferentes concepciones que aparecen en los discursos acerca del barrio. Es una forma de operacionalizar y por lo tanto cristalizar las respuestas, pero no se trata con ello de plantear discursos coherentes u homogéneos, sino de dotarnos de una técnica que permita ordenar ciertos sentidos acerca de los lugares. Dado que las categorías no son estancas, sino que pretenden dar cuenta de cierto movimiento a través de la posibilidad de posiciones intermedias o a caballo entre ellas, este enfoque nos parece especialmente sugerente para el tema que nos ocupa.

En el primero de ellos, el Yo, encontramos las significaciones de carácter personal/experiencial vinculadas a etapas vitales y conectadas con diferentes emociones, aquellas que se vinculan con actividades específicas o las que sirven para explicar aspectos de su identidad personal.

"De hecho es verdad, yo soy tan... yo soy de Vallecas y soy del Rayo." E2.

En el cruce Yo/Otros opera la conciencia de reconocer y ser reconocidos, por lo tanto el juego entre el sentido de comunidad y el anonimato como re-creaciones que se conjugan sobre la espacialidad del barrio.

"Cuando a ti te conoce la gente, estás más seguro en un barrio bajo que todo el mundo te conoce y sabe quién eres y no tienes ningún problema que en un barrio que nadie conoce." A8

"Yo me siento del barrio porque como te dije antes, conozco a todos los vecinos, porque que me conocen que yo tenía niños hace cinco años y los cuidaba a ellos solos, me conocían todos los vecinos, todo el barrio, toda la gente, yo no tengo ningún problema sobre eso, con los vecinos, con los amigos, todo el barrio no tenemos nada, ni negro, ni blanco, ni nada, todo igual." A3.
El campo Otros es el espacio de los estereotipos. Los significados se construyen a partir de las imágenes acerca de las prácticas o características de quienes habitan el espacio. Es el campo de las comparaciones binarias entre el aquí y el allí, el ellos y el nosotros.

"Hablo con muy pocos, con muy pocos vecinos. Porque te miran como por encima del hombro no sé... Y yo la verdad es que yo soy igual que tú (...) No le encuentro el sentido, muchas veces les saludo y se quedan callados, pues ya digo a esta persona no la saludo, no me voy a morir porque no te salude oye que... tampoco te vas a morir porque te den los buenos días y lo contestes, entonces no, no... muy poco, con muy pocos." E10.

En el cruce Otros/Entorno, tal vez el más difícil de captar, lo que opera es una suerte de proyección de las identidades de los habitantes o usuarios hacia el espacio que ocupan, la descripción se establece en términos de "modos de vida" "ambiente", "clima”, "atmósfera”.

"O sea, el barrio, si tú paseas por el barrio, no es un barrio que te vaya a invitar a estarte... es un barrio muy de clase, a nivel de vista, de clase media baja. Cuando tú paseas por él, tú lo ves, vamos, yo por lo menos es una sensación con la que me quedo, y quiero decir, no lo catalogo moralmente, lo que veo es..." A1.

En el vértice de Entorno se ubican aquellos significados referidos al paisaje urbano así como los aspectos simbólicos o históricos vinculados al lugar o elementos de orden institucional, la localización en relación con otros lugares o las actividades que allí se desarrollan.

"No deja de ser un barrio que lo han hecho estanco por todas partes está estanco entonces, su forma de relacionarse con la ciudad es como si fuera un poblado de verdad hasta para sus vecinos." E4.

"Este era el concepto: aquí están los trabajadores y van allí a trabajar pero cuando vuelvan los recursos están limitados a esta zona porque hemos puesto seis carriles de A3, el tren y la M30." E4.

En el cruce entre el Entorno y el Yo, lo que operan son los conocimientos tanto formales como familiares que las personas tienen sobre el lugar y las oportunidades que el mismo ofrece.

"Bueno yo llegué aquí en este barrio en el 70. Y en el 70 no había tan solo aquí una Colonia, que le llamábamos la Colonia de la Paz, y luego estaban los 500, donde está el Centro de Mayores, y ahí en frente ese bloque que hay ahí atrás y todo ese solar eran los 500. Y luego estaban las domingueras, que son las calles de abajo. Pero aquí en este recinto, eran los 500 y los nuestros. Todo 
lo demás estaban todo barro, sin nada. Todo el parque era una escombrera, ahí salían ratas. De la escombrera salían muchas ratas..." E1.

Del análisis de los discursos sobre los barrios analizados se desprende que esta relación triangular en la que se articulan los significados acerca del lugar sobre el eje planteado - YoOtros-Entorno- aparece como un conjunto de sentidos que evocan las vinculaciones que se despliegan sobre los barrios. Si bien son articulaciones variables, conflictivas y sujetas a transformaciones, la propuesta interpretativa da cuenta de las múltiples dimensiones de los lugares y del carácter complejo de los mismos. Es por ello que las formas de aproximación al estudio de los lugares deben tener en cuenta las movilizaciones y sedimentaciones que operan tanto en lo simbólico como en lo material en base a las evocaciones que sus habitantes hacen del mismo. Tal y como plantea Pedro Limón:

"la construcción de un sentido del Lugar propio está inextricablemente unida a la configuración de un sentido específico de barrio, e implica no sólo la estructuración de formas de contestación, negociación y reproducción de los imaginarios y significados políticos en disputa, sino la redefinición de los significados y referentes políticos en clave de barrio." (LIMÓN, 2015: 266).

Por último, cabe señalar las diferencias en los procesos de apropiación e identificación sobre el barrio que los distintos agentes/vecinos hacen del mismo. Si hasta ahora el recorrido, a modo casi de cartografía, se centraba en las conexiones del entorno, la historia y los lugares como conjunto de sentidos y emociones en este último apartado se identifican las diferencias a partir de las percepciones que se elaboran con base a las diferencias entre los propios vecinos.

Tres categorías se configuran como identidades con procesos muy diferenciados en cuanto a la proyección de los vínculos y sentidos sobre el barrio. Estas tres categorías están profundamente vinculadas con la dimensión temporal, fundamentalmente en cuanto que tiempo transcurrido en el barrio.

La primera categoría es mucho más fuerte que las otras dos analizadas. Leída de forma habitualmente más conflictiva manifiestan unas formas de apropiación espacial profundamente territorializadas y en muchos casos muy expansivas en el uso y la visibilidad sobre el espacio público. Siguiendo el esquema propuesto de la relación triangular de GUSTAFSON (2001) las pautas espaciales observadas en los discursos analizados así como en el conjunto del trabajo de campo, denotan una comunidad con lazos muy sólidos donde los procesos de reconocimiento establecen conexiones hacia el interno, marcando mucho la posición ellos/nosotros. Al mismo tiempo estas pautas se arraigan mucho sobre el territorio desplegando sobre el barrio-el hogar-el culto religioso, como institución fundamental en la ordenación comunitaria y sus actividades económicas, habitualmente vinculadas al establecimiento de un mercado al aire libre.

\footnotetext{
“(...) - hablando del culto- sobre todo tiene una función social, que es muy interesante en ese sentido. Por eso yo creo que muchas veces la gente infravalora la labor de, independientemente de que sea religioso o no, yo no soy especialmente religiosa, pero a mí me parece muy interesante la función que hace la Iglesia, ¿no? (...), porque nosotros, a los chavales del barrio lo que están haciendo es alejarles de las drogas, alejarles del alcohol. Ahora mismo, por ejemplo, está proliferando mucho por los barrios el tema de los juegos. Es la nueva droga..." A8.
}

Empleamos el concepto de identidades en la diáspora, porque opera en ellos de manera simultánea la idea de tránsito así como unas pautas muy arraigadas sobre el territorio. Elemento que tiene que ver con la edad temprana en la que acceden a la maternidad y la paternidad.

“(...) Aquí son muy jóvenes, aquí han empezado a tener hijos a los 15 o 16 "GAL1.

Este hecho supone, en la mayoría de los casos la paralización de su proceso de formación académica y la dificultad por lo tanto de trayectoria profesional independiente de las redes comunitarias que establecen al interno. El barrio adquiere una relevancia fundamental pues en el eje Yo-Entorno este aparece como el soporte sobre el cual se articulan todos los elementos de sostenibilidad y reproducción social, en términos comunitarios e individuales, dado que estos están inextricablemente contenidos en los primeros.

Otra categoría está vinculada a las diferencias generacionales. En la relación Yo-EntornoOtros, las personas mayores crearon un vínculo tanto con el territorio como con el vecindario. Las dinámicas Yo-Entorno se caracterizan por diferentes elementos: la construcción material del barrio, las proyecciones futuras sobre y en el mismo y, finalmente, la vida cotidiana con sus recorridos y las costumbres barriales. La relación Yo-Otros, por otro lado, se construyó sobre una base cultural bastante homogénea, esta ventaja facilitó el reconocimiento recíproco entre vecinos y como consecuencia el desarrollo de cierto tipo de vida comunitaria y de 
solidaridad. El pasado chabolista y las luchas vecinales por la conquista del hogar contribuyeron al "desarrollo de una trama ${ }^{4}$ vinculado a una historia concreta y capaz de movilizar a los vecinos alrededor de temas sociales relevantes" (HART, 1992: 633-634). En el cruce entre estas tres dimensiones se fue desarrollando, por un lado, una identidad barrial, vinculada a las proyecciones futuras: la conquista o la entrega de un hogar conllevó una mayor seguridad sobre la permanencia en el territorio y como consecuencia la posibilidad de verse en él en el futuro, territorializarlo y comprometerse. El desarrollo de un sentimiento identitario ligado al ambiente, al territorio, es de fundamental importancia porque incrementa los sesgos motivacionales (DEVINEWRIGHT \& CLAYTON 2010: 269). De hecho, estas condiciones iban poniendo las bases para la creación de un barrio agradable, familiar, cotidiano, donde desarrollar todas las actividades opcionales, un barrio donde descansar y en definitiva pasar tiempo.

La trama de las personas mayores si bien tuvo una función socializante y aglutinadora por aquel entonces, no puede encajar con la realidad de los jóvenes criados en un contexto globalizado y menos homogéneo. Ellos no parecen haberse creado su propia trama e identidad basados en la relación Yo-Otros según las características propias de los Otros, su identidad resulta más bien ligada al lugar, no comparten una historia común con sus coetáneos, no parecen tener, entre ellos, una conexión generacional, sin embargo, comparten un presente en un lugar concreto. La identidad del Yo parece estar más bien relacionada con el cariño familiar, los recuerdos infantiles y el apego a la idea de barrio de toda la vida. Lo que resulta interesante es que en la relación Yo-Entorno no hay una verdadera apropiación territorial, es decir, el espacio del barrio no es, por norma general, la mejor opción para salir a darse un paseo o una vuelta, las rutinas diarias se limitan a lo necesario. Los jóvenes, sobre todo aquellos cuya historia familiar se vincula al barrio, perciben un cambio a peor del mismo lo cual implica o bien el irse o bien un cambio de actitud hacia el mismo (WESTERHERBER, 2004: 112). De hecho, si bien el cariño hacia el barrio no se puede negar, lo que viene a faltar son las proyecciones futuras en el mismo por parte de esta generación, el quedarse en el barrio parece vincularse a una mezcla entre la dificultad de irse, por cuestiones económicas, y las ganas de quedarse por los recuerdos que les evocan los espacios barriales, la presencia de la familia y de los amigos.

Finalmente, la categoría de los migrantes cuya expresión identitaria vinculada al barrio varía según la generación. Los adultos, se vinculan al barrio en el plano Yo-Otros, su identidad barrial depende en mayor medida de las relaciones sociales que entrelazan y, a pesar de que el despliegue de estas se materialice en el mismo territorio, no son los lugares concretos que les ligan al barrio, si no la vida que en ellos desarrollan. La cotidianidad y las rutinas forman parte de la identidad por las relaciones que entrelazan con los vecinos, se conocen, se reconocen, se identifican por las circunstancias comunes uno con el otro. Las proyecciones futuras sobre el territorio del barrio se ven frustradas por la incertidumbre de su situación personal, por lo tanto, la dimensión Yo-Entorno, cobra, en el desarrollo identitario, menor importancia.

Los jóvenes, migrantes de segunda generación, sin embargo, vinculan su identidad tanto al territorio del barrio, en el plano Yo-Entorno, como a las relaciones con los vecinos, Yo-Otros. Los espacios y los lugares del barrio les representan, pero tienen una visión más crítica sobre ellos, entre los jóvenes, a pesar de haber desarrollado su vida allí tienen sentimientos en contra. Por un lado, les gustaría mejorar su situación y por ello irse del barrio y por el otro, si el barrio mejorara, les gustaría quedarse en virtud de los vínculos sociales que tienen, que forman parte de sus vivencias y de su identidad. La relación de esta última, cuando está formada, con el espacio físico es, de hecho, relevante, siendo que este juega un papel importante (WESTER-HERBER, 2004).

\section{A modo de conclusión. El barrionalismo como práctica política}

Como hemos visto a lo largo del artículo, el barrio, como dimensión múltiple, conflictiva y compleja, opera en tanto que espacialidad/lugar, local y al mismo tiempo conectada en una red pluriescalar, productor y producto de identidades, así como depósito de significados y afectos. Los barrios, como conjuntos espaciales como parte de la unidad más amplia de ciudad, no operan solo o fundamentalmente en su funcionalidad administrativa, sino que desvelan

\footnotetext{
4 Traducción propia de la palabra emplotment: narración construida a partir de una serie de eventos históricos reales vinculados a una trama común (HART: 1992).
} 
lugares y espacialidades singulares que conforman universos de sentido. Al mismo tiempo, tal y como señalan Marta Domínguez y Margarita Barañano, "estas representaciones cristalizan en el contexto de otros cambios físicos, materiales y estructurales."(BARAÑANO \& DOMÍNGUEZ, 2018: 281).

La complejidad en el estudio de los barrios tiene que ver con las múltiples dimensiones que hacen parte en la conformación de esos universos. En esta propuesta se han dimensionado su carácter espacial, histórico y discursivo por su relevancia en la conformación de las identidades. Es necesario entender que esas identidades se articulan en momentos específicos y que por lo tanto, lejos de ser estancas, se transforman y reifican constantemente si bien es posible trazar ciertas continuidades que se adivinan en las percepciones y sentidos que operan en esas espacialidades.

La crisis del Estado Nación en cuanto que modelo espacial y la eclosión de un juego constante de escalaridades lejos de eliminar los aspectos particulares que posibilitan vínculos comunitarios los transforman en modos más complejos, desplegándose sobre el territorio, sobre lo próximo, una serie de estrategias y marcos de sentido que reconfiguran imágenes comunitarias abigarradas y que adquieren más relevancia conforme más se hace patente el proyecto globalizador. Si bien las fuerzas productivas tienden a la homogeneización de los espacios (LEFEBVRE, 2013) como práctica política, contienen al mismo tiempo la fragmentación, y, en ella, la posibilidad de agencia de los sujetos puede devenir en procesos de apropiación y afirmación comunitaria. Si la ciudad global (SASSEN, 2015) alteró las geografías del sistema mundo, generando nuevos nodos de concentración de poder y flujos económicos, abrió la puerta a lo local como nueva geografía globalizada, y por lo tanto no solo como receptáculo de influjos y procesos del exterior, sino también como productor de nuevas formas y prácticas políticas y simbólicas. El barrio cobra relevancia por su posición como espacio frontera entre lo público y lo privado, lo homogéneo y lo particular. En los contextos estudiados estos elementos aparecen en distintas intensidades y en muchos casos conflictivas y contradictorias. No se trata de defender identidades unívocas o exentas de contradicciones, como de señalar que:

"el barrio se ha vuelto a reivindicar como espacio de resistencia y de creatividad comunitaria y asociativa contra la exclusión social" (PRADEL, 2018: 25)

y es precisamente a partir de la práctica política de resistencia y de la posibilidad del despliegue de relaciones comunitarias de solidaridad, que esas identidades se connotan de formas más relevantes conforme el proyecto globalizador más se empeña en unificarlas.

Estos procesos de apropiación se observan en barrios donde los elementos que hemos planteado en el análisis operan en formas relacionales entre sí, de tal manera que se reifican para constituirse en barrionalismo, un:

\footnotetext{
"tipo de identificación basada en un reconocimiento de horizontalidad social con respecto al otro, en una aceptación compartida de un origen común y, finalmente, en una delimitación espacial generalmente aceptada alrededor de un territorio reconocido y nombrado como propio" (LIMÓN, 2015: 270).
}

No se trata de una suma de condiciones que en el contexto globalizador dan como resultado prácticas de apropiación identitarias, ni entendemos tampoco que todos los procesos identitarios operan de la misma forma. No podemos, en este sentido anticipar las respuestas de forma mecánica, sino que debemos atender a cada particularidad y a cómo las espacialidades se convierten en depósitos de sentidos y prácticas transformadoras. En los tres casos estudiados solo afirmamos este tipo concreto de articulación en el caso de Entrevías, donde tanto el diseño y trazado urbano que permite la diversidad, como la condensación de luchas y reivindicaciones políticas sostenidas a lo largo del tiempo, construyen un simbólico en el que reconocerse, articulando la posibilidad de resistencias no solo materiales como también identitarias. Hay una suerte de orgullo Vallekano que en Entrevías no se ha perdido con el paso del tiempo, y este orgullo se vincula a una historia concreta de reivindicaciones, de logros, de rebelión en contra de la injusticia, pero también de solidaridad y ayuda mutua. Todas estas características encuentran precedentes históricos en el barrio de Entrevías permitiendo una identificación de los sujetos y por ende una mayor predisposición al compromiso con el territorio. Propio, que está constituido por nuestras conductas cotidianas y nuestra significación de éstas a través de la experiencia diaria y por las formas de socialización espacial aprendida y contestada desde el propio entorno.

\section{Bibliografía}

Barañano Cid, M. \& Domínguez PéRez, M. (2018): Desplazamientos identitarios en tres barrios madrileños de promoción oficial. entre la postradicionalización y el envejecimiento, OBETS. Revista de Ciencias Sociales, Volumen 13, n. ${ }^{\circ}$ 1: 257-288. 
BRAH, A. (2011): Cartografías de la diáspora: identidades en cuestión, Madrid, España, Traficantes de sueños.

BoRDETAS JIMÉNEZ, I. (2017): Aportaciones del activismo femenino a la construcción del movimiento vecinal durante el tardofranquismo. Algunos elementos para el debate. Historia Contemporánea, n. ${ }^{\circ}$ 54: 15-45.

BALFouR, S. (1994): La dictadura, los trabajadores y la ciudad: El movimiento obrero en el área metropolitana de Barcelona (1939-1988), Valencia, España, Alfons el Magnànim.

BARTHES, R. (2007): El imperio de los signos, Barcelona, España, Seix Barral.

BeRTRAND, M. J. \& LozANO, J. V. (1981): La ciudad cotidiana, Madrid, España, Madrid: Instituto de Estudios de Administración Local.

Brown, B., Perkins, D. \& Brown, G. (2003): Place attachment in a revitalizing neighborhood: Individual and block levels of analysis. Journal of Environmental Psychology, n. ${ }^{\circ}$ 23: 259-271.

Caries Martí, R., López de Lucio, R. \& Hernandez AJA, A. (1995): "Ensanches en la periferia. El caso de Madrid". En LóPEZ DE LUCIO, R. \& HERNÁNDEZ AJA, A. (Eds.) Los nuevos ensanches de Madrid: la morfología residencial de la periferia reciente, 1985-1993 (pp. 259-262), Madrid, España, Gerencia Municipal de Urbanismo del Ayuntamiento de Madrid, D.L. 1995.

CARR, S. \& al. (1992): Public Space, Cambridge, Uk, Cambridge University Press.

CASTELls M. (1977): Ciudad, democracia y socialismo: la experiencia de las asociaciones de vecinos en Madrid, Madrid, España, Siglo veintiuno de España editores.

- (2012): Reti di indignazione e speranza: movimenti sociali nell'era di internet, Milano, Italia, Università Bocconi.

DACONTO, L. (2014): "Lo spazio pubblico nella città contemporanea. Evoluzioni e cambiamenti nella relazione tra urbano e dimensione pubblica", in Bergamaschi, M., CASTRIGnANò, M., (Eds.) La città contesa, popolazioni urbane e spazio pubblico tra coesistenza e conflitto, (pp.31-48), Roma, Italia, FrancoAngeli.

DEVINE-WRIGHT, P. \& CLAYTON, S. (2010): Introduction to the special issue: Place, identity and environmental behaviour. Journal of Environmental Psychology, n. ${ }^{\circ}$ 30: 267-270.

Di Febo, G. (2006): Resistencias femeninas al franquismo. Para un estado de la cuestión. Cuadernos de historia contemporánea, n. ${ }^{\circ} 28$ : 153-168.

Dı MÉo G. (1991): L'homme, la société, l'espace, Paris, Francia, Anthropos.

ERREJón GALVÁN, I. (2011): El 15-M como discurso contrahegemónico. Encrucijadas. Revista Crítica de Ciencias Sociales, n. ${ }^{\circ}$ 2: 120-145.

EZQUIAGA, M. (1990): Formas construidas, formas del suelo. Reflexiones en torno a los nuevos proyectos de extensión residencial, Geometría, volumen 2, n. ${ }^{\circ}$ 8: $2-23$

GEHL, J. (2006): La humanización del espacio urbano: la vida social entre los edificios, Barcelona, España, Editorial Reverté.
Gould, P., \& White, R. (1986): Mental Maps, sec. Edition. Boston/London, Uk, Routledge.

Gravano, A. (2005): El barrio en la teoría social, Argentina, Espacio Editorial.

GustAFson, P. (2001): Meanings of place: Everyday experience and theoretical conceptualizations. Journal of environmental psychology, Volumen 21 , n. ${ }^{\circ}$ 1: 5-16.

HART, J. (1992): Cracking the code: narrative and political mobilization in the greek resistance, Social Science History, vol 16, n. ${ }^{\circ}$ 4: 631-668.

JACOBS, J. (2011): Vida y muerte de las grandes ciudades (A. Abad y A. Useros, trad. Orig., 1961), Madrid, España, Capitán Swing.

KAPLAN, T. (1999): "Luchar por la democracia: formas de organización de las mujeres entre los años cincuenta y los años setenta". En Aguado A. (Eds.) Mujeres, regulación de conflictos sociales y cultura de la paz, (pp. 89-108), Valencia, España, Servei de Publicacions.

Leal Maldonado, J. (2002): Segregación social y mercados de vivienda en las grandes ciudades, Revista Española de Sociología, n. ${ }^{\circ} 2$ : 59-75.

LefEBVRE, H. (1972): La vida cotidiana en el mundo moderno, Madrid, España, Alianza Editorial.

— \& LoREA, I. M., \& GuTIÉRREZ, E. M. M. (2013): La producción del espacio, Madrid, España, Capitán Swing.

LIMÓN, P. (2015): Un barrio para gobernarlos a todos: gentrificación, producción de globalidad y barrionalismo en Hortaleza (Madrid) y Poblenou (Barcelona) (Doctoral dissertation, Tesis doctoral. Universidad Complutense de Madrid).

LYNCH, K. (1960): The image of the city, Cambridge, USA, MIT Press.

MANNHEIM, K. (1998): Saggi di sociologia della cultura, Roma, Italia, Armando.

MARGULIS, M. (2002): La ciudad y sus signos. Estudios sociológicos, volumen $\mathrm{XX}, \mathrm{n} .^{\circ}$ 3: 515-536.

MASSEY, D. (1994): Space, Place and Gender, Mineápolis, Minnesota, University of Minnesota Press.

MERRIFIELD, A. (1993): Place and space: a Lefebvrian reconciliation. Transactions of the institute of British geographers, volumen 18, n. ${ }^{\circ}$ : : 516-531.

Pradel, M. \& García CABeza, M. (2018): El momento de la ciudadanía: innovación social y gobernanza urbana, Madrid, España, Catarata.

ONTAÑóN, M. J., \& MoRALES, J. M. L. P. (1971): Bloques complementarios de pantalla en el sector de Pan Bendito. Madrid. 608 viviendas y edificios complementarios. Hogar y arquitectura: revista bimestral de la obra sindical del hogar (97), 3.

OSLENDER, U. (2002): Espacio, lugar y movimientos sociales: hacia una espacialidad de resistencia. Scripta Nova, Volumen 6, n. ${ }^{\circ} 115$.

PASQUI, G. (2008): Città, popolazioni, politiche, Milano, Italia, Jaca Book.

PASTOR, J. (2012): El movimiento $15 \mathrm{~m}$ en Madrid, 2012. Anuario del Conflicto Social. 0(2), 205-2014.

SASSEN, S. (2015): Espulsioni: brutalità e complessità nell'economia globale, Bologna, Italia, II mulino.

SAUSSURE, F. D. (1945): Curso de lingüística general, Buenos Aires, Argentina, Losada. 
Schuman, H. \& ScotT, J. (1989): Generation and collective memories, American Sociological Review, volumen 54, 359-381.

SMALL, M. (2011): Villa Victoria: povertà e capitale sociale in un quartiere di Boston, Milano, Italia, Franco Angeli.

SUBIRATS, J. \& GARCIABERNARDOS, A. (2015): Innovación social y Políticas urbanas en España, Barcelona, España, Icaria.

SuDJIC, D. (2017): El lenguaje de las ciudades, Barcelona, España, Editorial Ariel.

TUAN, Y. F. (1974): Space and place: humanistic perspective. Progress in geography, $n .{ }^{\circ}$ 6: 211-252.
- (1977): Space and place: The perspective of experience, Mineápolis, Minnesota, University of Minnesota Press.

UCEDA NAVAS, P. (2017): La ciudad desequilibrada. El derecho a la ciudad en los barrios vulnerables de Madrid (Doctoral dissertation, Universidad Complutense).

Wester-HeRber, M. (2004): Underlying concerns in land-use conflicts-the role of place-identity in risk perception. Environmental Science \& Policy, n. ${ }^{\circ}$ : 109-116. 